ÉGYPTE

monde arabe

\section{Égypte/Monde arabe}

22| 1995

Géographies de l'Égypte 1

\title{
Géographie de l'Égypte I : introduction
}

\section{François Moriconi-Ebrard}

\section{(2) OpenEdition}

Journals

Édition électronique

URL : https://journals.openedition.org/ema/591

DOI : 10.4000/ema.591

ISSN : 2090-7273

\section{Éditeur}

CEDEJ - Centre d'études et de documentation économiques juridiques et sociales

\section{Édition imprimée}

Date de publication : 30 juin 1995

Pagination : 7-10

ISSN : 1110-5097

\section{Référence électronique}

François Moriconi-Ebrard, «Géographie de l'Égypte I : introduction », Égypte/Monde arabe [En ligne], 22 | 1995, mis en ligne le 08 juillet 2008, consulté le 07 juillet 2022. URL : http:// journals.openedition.org/ema/591; DOI : https://doi.org/10.4000/ema.591

Ce document a été généré automatiquement le 7 juillet 2022.

Tous droits réservés 


\title{
Géographie de l'Égypte I : introduction
}

\author{
François Moriconi-Ebrard
}

1 En 1993-94, grâce au soutien du CNRS (PIR-Villes) et du Ministère des Affaires étrangères, l'Observatoire Urbain du Caire Contemporain (OUCC) a été doté de nouveaux moyens en personnel et en équipements. Ainsi cette structure de service, créée au sein du CEDEJ en 1984, s'est-elle progressivement transformée en unité de recherche, et divers programmes collectifs et individuels y ont vu le jour. Si, comme son nom l'indique, l'OUCC était initialement chargé de soutenir les recherches sur la ville du Caire, il est vite apparu que la métropole égyptienne ne pouvait être enfermée ni dans son cadre territorial administratif (le gouvernorat du Caire ne couvre qu'une partie de l'agglomération), ni dans son enveloppe morphologique (on vient quotidiennement travailler au Caire depuis des villes de province distantes de plusieurs dizaines de kilomètres), pas plus que l'on ne pouvait détacher cette ville-monde de certains enjeux géostratégiques ou économiques régionaux ou mondiaux. Ainsi, sans abandonner leurs objectifs premiers, les centres d'intérêt de I'OUCC se sont élargis à d'autres villes du pays, puis au système territorial de l'Égypte, voire, pour certains thèmes, à des comparaisons internationales, toutes approches que la recherche urbaine contemporaine ne saurait ignorer.

2 La mise en place des programmes en cours est donc passée par différentes phases de préparation, notamment par l'élaboration d'un outil pour la recherche : le système d'information géographique «EGIPTE ${ }^{1}$. Du fait de son envergure, ce système n'était opérationnel qu'en partie au moment de la réalisation de ce dossier: certaines contributions ont néanmoins pu s'appuyer sur cet outil, qui sera prochainement disponible pour l'ensemble du territoire égyptien.

3 Au cours de l'année 1994-95, l'OUCC a également coordonné un séminaire à base disciplinaire. Cet atelier réunissait neuf doctorants en géographie ou en urbanisme, ainsi que des chercheurs du CEDEJ. Sa vocation consistait en un échange méthodologique et bibliographique, et des chercheurs extérieurs à l'institution ont été invités à venir y participer, apportant soit leur expérience dans une discipline donnée 
(démographie, sociologie, géographie, urbanisme) soit un éclairage particulier sur leurs connaissances de la société et du territoire égyptiens.

4 Pour l'heure, les contributions recueillies dans le présent volume relèvent toutes de recherches individuelles : elles sont d'une grande diversité, tant par le lieu ou l'échelle choisis par leurs auteurs que par l'originalité de leurs approches.

5 Malgré cette diversité, ces « géographies de l'Égypte » sont unies par un fil conducteur, que l'on peut saisir quel que soit le côté par lequel on aborde le territoire et la société de ce pays : celui de la centralisation. C'est dans cet objectif de synthèse que se situe le premier article (F. Moriconi), qui montre combien il est difficile de dissocier Misr (l'Égypte) et Masr (Le Caire, en arabe dialectal). En d'autres termes, il s'agit d'expliquer comment les logiques des politiques centralisatrices et des traditions administratives et territoriales, participant d'un véritable «consensus national», s'inscrivent profondément dans la société et le territoire égyptiens. Cette relecture multi-scalaire de la géographie du pays soulève en particulier un problème ubiquiste : l'Égypte de demain glisserait-elle sur ses marges?

C'est également à travers le prisme des comparaisons que Ph. Fargues aborde les problèmes socio-démographiques du Caire, articulant l'échelle du Monde arabe avec celle de l'agglomération du Caire, cartographiée au niveau de son découpage territorial le plus fin : celui de la shiyâkha. A cette dernière échelle - celle de la métropole -, il remarque que le glissement de l'urbanisation vers la périphérie s'accompagne d'une déprise du centre. L'article de J. Seguin et 0 . Sanmartin conduit aux mêmes conclusions quant aux nouvelles segmentations sociales de la société égyptienne et aux nouvelles fractures du tissu économique engendrées par l'infitâh (ouverture économique) : la dialectique centre-marges se lit également à l'échelle du pays.

7 Ainsi, l'arrivée massive d'investissements, l'irruption de touristes porteurs de valeurs exogènes, la présence, sur les marges du pays, de rentes dépendant quasi exclusivement de la demande extérieure sont, à toutes les échelles, susceptibles de bouleverser les grands équilibres de la nation. Ces transformations posent la capacité de ce modèle à entraîner, dans son sillage l'ensemble du pays sur la voie du développement. L'approche socio-spatiale proposée par A. Madœuf, relative à un espace considéré comme le " cœur » de la cité, c'est-à-dire, dans ce système centralisé, comme l'âme du pays montre l'ambiguïté de ces valeurs : l'auteur montre que la « ville ancienne» d'aujourd'hui est un espace contrasté qui se laisse difficilement appréhender par les modèles classiques de la géographie sociale. M. Guillet, quant à elle, s'interroge sur la permanence d'un lieu, le quartier au nom sans équivoque de "Garden-City", dont la centralité glisse d'une substance sociale - l'aristocratie coloniale-égyptienne - à une substance économique - bancaire et financière.

8 A. Waguih, enfin, reflète une perspective de la recherche égyptienne en urbanisme, qui désire répondre à l'inquiétude officielle que suscite le mode de développement mal connu de certains quartiers périphériques.

9 Ce dossier «Géographies de l'Égypte» fera l'objet d'une seconde partie dans la prochaine livraison d'Égypte/Monde arabe ( ${ }^{\circ}{ }^{23}$, troisième trimestre 1995). 


\section{NOTES}

1. Le système d'informations géographiques informatisées « EGIPTE » (Explorations géographiques informatisées sur le territoire et la population de l'Égypte), élaboré à l'OUCC en 1994-95, comprend 8 millions de données fournies par le Capmas (Central Agency for Public Mobilization and Statistics) couvrant 1400 informations statistiques pour chacune des 5000 unités locales de l'Égypte, et un siècle de recensements (1882-1986).

INDEX

Mots-clés : géographie

\section{AUTEUR}

FRANÇOIS MORICONI-EBRARD

CEDEJ-OUCC 